\title{
Мониторинг ресурсов электронного участия: методика и некоторые результаты
}

\author{
Ю. А. Кабанов ${ }^{1,2}$, Г. О. Панфилов ${ }^{1}$, А. В. Чугунов ${ }^{1}$ \\ ${ }^{1}$ Университет ИТМО, ${ }^{2}$ НИУ Высшая школа экономики - Санкт-Петербург \\ kabanov_igud@mail.ru, panfilovgeorg@mail.ru, chugunov@itmo.ru
}

\section{Аннотация}

В статье представлены основные результаты комплексного исследования ресурсов электронного участия в регионах России, осуществленного в декабре 2019 - январе 2020 г. Исследование проведено с использованием методики, позволяющей оценивать различные инструменты электронного участия и проводить межрегиональные и кроссплатформенные сравнения. Методика была применена для оценки 198 региональных и 155 муниципальных ресурсов шести основных типов во всех 85 регионах России. В итоге построен рейтинг регионов по общему уровню развития электронного участия: выделено 23 региона с высоким уровнем развития ресурсов, 24 - со средним и 38 регионов - с низким. Результаты исследования подтвердили наличие существенных диспропорций регионального и муниципального развития электронного участия в России: как с точки разнообразия каналов, предоставляемых гражданам в разных городах и субъектах, так и с точки зрения качества их функционирования. Общим выводом является то, что на данный момент более активно развиваются «информационные» формы электронного участия. В дальнейшем планируется проведение ежегодного мониторинга развития электронного участия с использованием отработанной методики в сочетании с качественными методами.

Ключевые слова: информационные ресурсы, порталы электронного участия, e-participation, регионы России, мониторинг, рейтингование

Библиографическая ссылка: Кабанов Ю.А., Панфилов Г.О., Чугунов А.В. Мониторинг ресурсов электронного участия: методика и некоторые результаты // Государство и граждане в электронной среде. Выпуск 4 (Труды XXIII Международной объединенной научной конференции «Интернет и современное общество», IMS-2020, Санкт-Петербург, 17 - 20 июня 2020 г. Сборник научных статей). - СПб: Университет ИТМО, 2020. С. 61-72. DOI: 10.17586/2541-979Х-2020-4-61-72

\section{1. Введение}

Статья представляет основные результаты комплексного исследования российских систем, обеспечивающих взаимодействие органов власти с гражданами и представляющих собой каналы электронного участия. Работа является продолжением пилотных мониторинговых исследований состояния электронного участия в российских регионах, которые осуществлялись Центром технологий электронного правительства Университета ИТМО в 2017 и 2018 гг. Хотя в настоящий момент существует большое количество подходов к оценке на международном [1;2] и российском [3; 4] уровнях, большинство исследований ориентировано на анализ только определенных каналов участия, например, порталов электронных петиций [5; 6] или правительственных веб-сайтов [7; 8]. Вместе с тем, разнообразие каналов и технологий электронного участия в мире и России постоянно расширяется [9], в связи с чем возникает необходимость комплексной оценки всех 
имеющихся инструментов и вклада каждого из них в развитие электронного участия. В исследовании сделана попытка представить базовую модель функционирования разнообразных каналов электронного взаимодействия власти и граждан, определить специфику каждого канала, разработать систему оценки и провести мониторинг онлайнплощадок, обеспечивающих функционирование одного или нескольких каналов электронного участия. Следует отметить, что в нашем исследовании участвовали только те каналы, которые созданы региональными или муниципальными властями и имеющие соответствующий статус. Предлагаемая методика пытается решить эту комплексную задачу и оценить несколько каналов электронного участия, которые развиваются в России в настоящий момент - как на региональном, так и на муниципальном уровне.

Наша методология основана на системном подходе в политической науке [10], а также предыдущем опыте региональных мониторинговых исследований [3; 11], и ориентирована на оценку состояния развития шести основных каналов электронного участия.

Статья представляет промежуточные результаты выполнения проекта Российского научного фонда, ориентированного на комплексное исследование электронного участия граждан в контексте политического процесса и принятия политико-управленческих решений. Проект концентрируется на эмпирическом анализе существующих институтов и практик электронного участия, поиске наиболее успешных способов его использования для развития государственного и муниципального управления в Российской Федерации. В данном проекте термин «электронное участие» понимается как комплекс методов и инструментов, обеспечивающих электронное взаимодействие граждан и органов власти с целью учета мнения граждан в государственном и муниципальном управлении при принятии политических и управленческих решений [12].

Работа построена следующим образом. Вначале мы описываем институциональную модель электронного участия в России, которая позволяет, с одной стороны, выявить каналы электронного участия, на которые стоит обратить внимание, с другой, определить важный организационно-правовой контекст, в котором эти каналы функционируют. Далее, мы представляем саму методику оценки, с выделением концептов, индикаторов и их операционализации. В завершении формулируются предварительные результаты мониторинга электронного участия на региональном и муниципальном уровнях.

\section{2. Институциональная модель и методика исследования}

Российская специфика функционирования электронного участия заключается в том, что региональные платформы в определяющей степени связаны с активностью федерального центра [4; 13]. Конечно, имеются отдельные региональные и муниципальные инициативы, однако их жизнеспособность и устойчивость в значительной мере зависит от того, насколько конкретный проект (сайт, портал, информационная система) соответствует текущим установкам и решениям, принятым на федеральном уровне. Также важной специфической чертой российского подхода к развитию механизмов обратной связи власти с гражданами является использование информации о состоянии дел с обращениями и заявлениями граждан для организации контроля со стороны федерального центра за региональными и муниципальными элитами.

Чтобы определить место электронного участия в системе принятия решений, была разработана институциональная модель (рис. 1), отражающая основных участников, процессы и инструменты (каналы) электронного участия на местном и региональном уровнях. Эта модель является основой для предлагаемой методологии. Базисом модели является институциональная среда муниципального (регионального) устойчивого развития, в которую входят такие ключевые субъекты, как граждане, общественные объединения и бизнес. Логика этой модели заключается в том, что государственные институты влияют на окружающую среду (в идеале - позитивным образом через программы развития города / региона), формируя обратную связь. В свою очередь, 
гражданские субъекты помимо традиционных (офлайновых) каналов, используют различные инструменты электронного участия, чтобы направить свои требования (обращения, петиции) власти. Эти каналы представляют собой шесть важных инструментов электронного участия, а именно:

- электронные петиции;

сайты подачи жалоб и заявлений о необходимости решения различных проблем;

электронное голосование;

инициативное / партисипаторное бюджетирование;

открытый бюджет;

краудсорсинг.

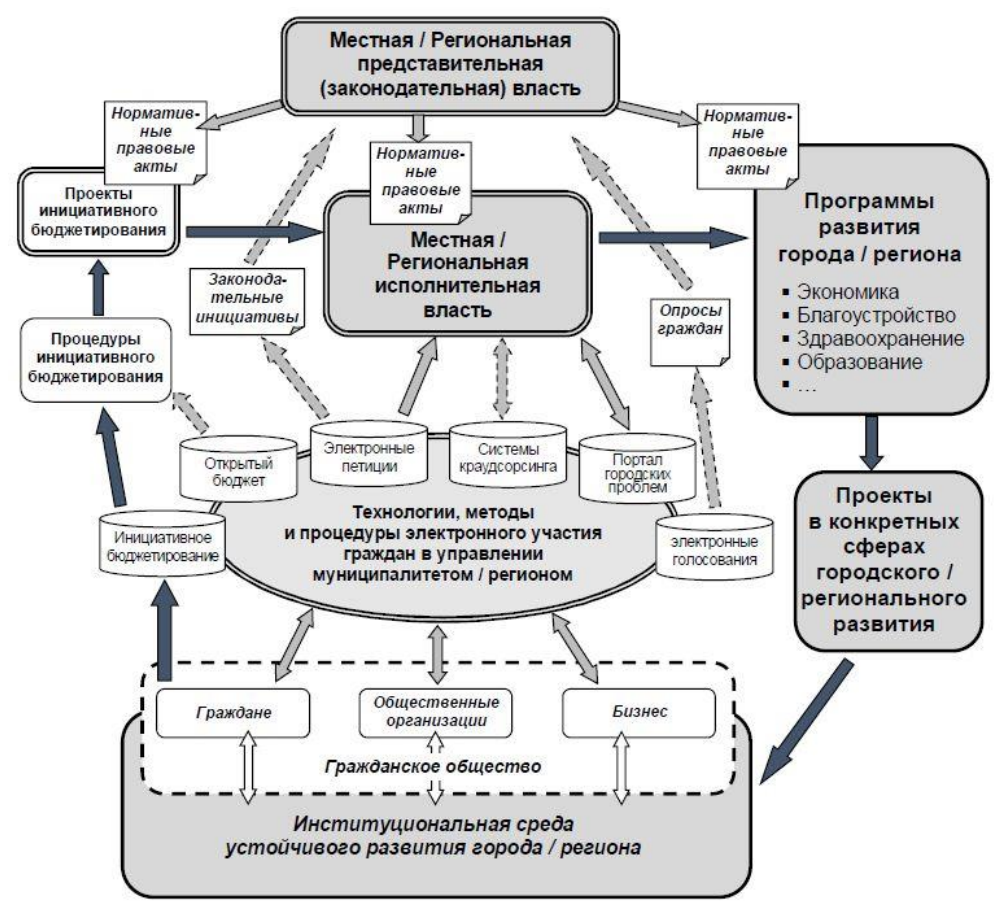

Рис. 1. Региональная институциональная модель электронного участия

В модели показано, что обратная связь обрабатывается правительством (местными / региональными законодательными и исполнительными органами) и реализуется институциональным образом через муниципальные или региональные программы и проекты развития, либо в «ручном режиме», используя для этого уже выделенные ресурсы. В этой модели мы выделяем как информационные каналы (светлые стрелки), так и каналы активности (темные стрелки), а пунктирные линии указывают на слабые звенья, то есть каналы, которые не играют в настоящее время существенной роли в текущей российской региональной и местной политике.

Анализ исследований и научных публикаций по проблемам электронного участия показывает, что до сих пор основное внимание уделялось двум каналам этого взаимодействия - жалобам на проблемы благоустройства и ЖКХ ( «Наш город Москва», «Наш Петербург» и др.) и электронным петициям (самые известные примеры независимый портал change.org и институциональный «Российская общественная инициатива»), тем самым сформировалось мнение, что механизмы электронного участия и функционируют исключительно через эти два основных канала. Наши предыдущие исследования (региональные мониторинги 2017 и 2018 гг. [11]) позволили выявить, что само явление существенно многообразнее, чем те практики, которые в настоящее время 
достаточно широко распространены. Это позволило внести корректировки в институциональную модель, обозначив выявленное многообразие каналов. На наш взгляд, важным уточнением стало включение в модель двух каналов взаимодействия: инициативного бюджетирования и ресурсов типа «Открытый бюджет», которые в настоящее время находятся в стадии развития и институционализации.

Предлагаемая нами методология основана на видении политического процесса согласно системному подходу в политической науке. Согласно Д. Истону [10], политическая система состоит из следующих базовых элементов: (1) собственно политическая система («черный ящик»), (2) «вход» («требования» и «поддержка» со стороны граждан); (3) «выход» (решения, политика); и (4) обратная связь (соответствие «входа» и «выхода»). Для каждого из этих концептов был определен критерий для оценки.

Концепт «Черный ящик» обозначается первым критерием «Открытость», характеризующим, насколько открыта, понятна и доступна пользователю информация, представленная на портале. Критерий включает следующие индикаторы:

актуальность (наличие признаков обновления сайта за последний месяц);

информирование об ответственности (наличие информации о целях, задачах портала, и ответственном органе власти);

воспринимаемость (наличие инфографики и возможности в 2 нажатия мышью перейти к основной информации портала).

Второй критерий, «Доступность», обозначает «Вход», фиксируя, насколько доступно для различных групп пользователей участие через анализируемый канал взаимодействия власти и граждан. Оценка осуществляется по следующим индикаторам:

версия ОВ3 (доступна ли на сайте версия для лиц с ограниченными возможностями); мобильность (доступны ли мобильная версия и мобильное приложение);

альтернативность (наличие информации об альтернативных возможностях участия в формате оффлайн: личное обращение в офис или МФЦ, почтовое обращение).

Концепт «Выход» относится к третьему критерию - «Принятие решений», показывающему, насколько на портале представлена информация по принимаемым решениям по обращению/инициативе пользователя. Критерий соотносится с индикаторами:

- региональное законодательство (наличие законодательных актов, регламентирующих деятельность данного ресурса);

отчеты (представление отчетов о результатах функционирования портала: кумулятивные отчеты, пресс-релизы, фотоотчеты);

маркеры диспетчеризации (наличие возможностей отследить статус обращения / инициативы - статусы заявок, ответственные лица / подразделения).

Четвертый критерий «Обратная связь», показывает, насколько «широки» возможности обратной связи пользователя. Данный критерий оценивается по индикаторам:

- контактная информация (доступность номера телефона, электронной почты, ссылок на аккаунты в социальных сетях);

оценка степени удовлетворенности (возможность оставить обратную связь в виде текста с оценкой функционирования системы, и видны ли эти оценки другим пользователям);

согласие с результатом (предоставлена ли возможность пользователям не согласиться с результатом и отправить заявление на повторное рассмотрение).

Также был сформирован пятый блок индикаторов -«Специфические требования к типу ресурса». Индикаторы в данном блоке являются уникальными для каждого из 6 типов порталов и отображают узкую функциональную специфику конкретного типа канала электронного участия. Индикаторы были отобраны на основе анализа нормативноправовой базы, а также выявления наиболее успешных примеров реализации ресурсов каждого типа с высокой пользовательской посещаемостью. Это было сделано в рамках двух этапов пилотного мониторинга в ходе разработки методики оценки. Например, для 
порталов сообщений о проблемах индикаторами стали наличие интерактивной карты событий, классификаторов сообщений, функции народного контроля.

Таким образом, методика мониторинга включает в себя 15 индикаторов, структурированных в 5 тематических блоков (по 3 индикатора в блоке). В ходе мониторингового исследования каждому информационному ресурсу выставлялась оценка от 0 до 2 баллов $(0$ - отсутствие информации или признака; 1 - частичное соответствие индикатору; 2 - полное соответствие). В случае порталов типа «Открытый бюджет» из оценки были исключены индикаторы «альтернативность», «маркеры диспетчеризации», «оценка степени удовлетворенности» и «согласие с результатом», поскольку данные ресурсы не предполагают прямых обращений граждан и исключают функционал, оцениваемый данными индикаторами. Идеальной, согласно методике, является ситуация, при которой в регионе представлены все 6 каналов электронного участия на двух уровнях власти. Максимально возможное количество каналов - 12 (6 региональных и 6 муниципальных), максимально возможный балл, который мог набрать регион - 344 балла. На одном веб-ресурсе в случае его многофункциональности, может располагаться более одного канала связи.

\section{3. Результаты исследования}

Мониторинг региональных интернет-ресурсов электронного участия был проведен в декабре 2019 г. В каждом регионе были выявлены и оценены по вышеописанной методике ресурсы шести типов. Т.к. было выявлено, что во многих регионах ресурсы, обеспечивающие электронное участие, созданы органами местного самоуправления (инициативное бюджетирование, голосования и др.) и фактически дополняли набор каналов, реализованных региональной властью, было решено охватить мониторингом сайты, созданные муниципалитетами городов, являющихся столицами регионов. Анализ и оценка этих ресурсов был произведен в декабре 2019 - начале января 2020 г. На финальной фазе мониторинга из базы анализа были исключены ресурсы, информация на которых не обновлялась модераторами в течение одного года. В итоговую выборку вошли 198 ресурсов регионального и 155 - муниципального уровня. Обобщенные результаты мониторинга представлены в таблице 1 .

Таблица 1. Обобщенные результаты мониторинга порталов электронного участия

\begin{tabular}{|c|l|c|c|c|c|c|c|}
\hline \multirow{2}{*}{ № } & \multirow{2}{*}{$\begin{array}{c}\text { Тип информационного } \\
\text { ресурса }\end{array}$} & \multicolumn{2}{|c|}{ Кол-во ресурсов } & \multicolumn{2}{c|}{$\begin{array}{c}\text { Охват } \\
\text { регионов }\end{array}$} & \multicolumn{2}{c|}{ Средний балл ** } \\
\cline { 3 - 8 } & & Регион. & Муниц. & Кол-во & \% & Регион. & Муниц. \\
\hline 1 & Открытый бюджет & 83 & 77 & 85 & 100 & $12 / 22$ & $9 / 22$ \\
2 & Инициат. бюджетирование & 51 & 27 & 60 & 71 & $8 / 30$ & $8 / 30$ \\
3 & Сообщения о проблемах & 30 & 20 & 43 & 51 & $14 / 30$ & $11 / 30$ \\
4 & Эл. инициативы / петиции & 12 & 6 & 17 & 20 & $12 / 30$ & $13 / 30$ \\
5 & Электронные голосования & 13 & 20 & 28 & 33 & $12 / 30$ & $11 / 30$ \\
6 & Краудсорсинг & 9 & 5 & 13 & 15 & $11 / 30$ & $11 / 30$ \\
\hline & \multicolumn{1}{|l|}{ Итого *** } & $\mathbf{1 9 8}$ & $\mathbf{1 5 5}$ & $\mathbf{4 1}$ & $\mathbf{4 8}$ & $\mathbf{1 7}$ & $\mathbf{1 1}$ \\
\hline
\end{tabular}

\section{Примечания:}

*В столбце «Охват регионов» представлено число регионов, в которых присутствует минимум один ресурс, курируемый любым уровнем власти.

**В столбце «Средний балл» цифра в знаменателе означает максимальное количество баллов, которое может получить конкретный тип информационного ресурса.

*** В строке «Итого» значения первых двух столбцов («Кол-во ресурсов») обозначают общее количество ресурсов, а последующих четырёх («Охват регионов» и «Средний балл») - средние значения. 
В результате обследования было выявлено, что наиболее широко распространенным ресурсом (каналом взаимодействия) на сегодняшний день являются системы информирования о бюджетном процессе типа «Открытый бюджет». Во всех 85 регионах России на сегодняшний день имеется как минимум 1 такой ресурс. Вторыми по распространенности являются ресурсы, посвященные инициативному бюджетированию они представлены в 71\% регионов (в 18 регионах было выявлено параллельное функционирование и регионального и муниципального ресурса).

Порталы, обеспечивающие возможность подачи сообщений о проблемах, замыкают тройку лидеров - 51\%. Остальные три канала взаимодействия с гражданами (электронные петиции, голосования и краудсорсинг) в настоящее время реализованы менее чем в трети регионов. Системы электронных голосований являются единственным из 6 типов ресурсов, который более распространен на местном уровне. Качество реализации интернет-ресурсов электронного участия в среднем является более высоким у ресурсов регионального уровня (17 баллов - см. табл. 1), чем муниципального (11), хотя при рассмотрении каждого из типов в отдельности различие можно считать незначительным. На обоих уровнях встречались как оригинальные ресурсы высокого качества, удобные и понятные для использования, так и представленные формально ресурсы с некачественной, неактуальной и неудобной для использования информацией.

Отдельно стоит упомянуть об особенности реализации бюджетных ресурсов. На сегодняшний день органами власти используются две формы реализации «Открытого бюджета» и инициативного бюджетирования:

в виде отдельного портала;

в виде раздела на сайте регионального правительства/администрации муниципального образования или регионального финансового органа исполнительной власти/муниципалитета.

Оба типа используются примерно с одинаковой частотой. Более качественными, в большинстве случаев, оказывались ресурсы первого типа - в среднем, специально выделенные порталы получили больший балл при оценивании (15 баллов - «Открытый бюджет», 12 баллов - инициативное бюджетирование) в сравнении с разделами на сайте органов власти (9 и 6 баллов соответственно). Такой перевес был достигнут в первую очередь за счет показателей, касающихся актуальности и качества представления информации, а также расширенных функциональных возможностей порталов. Например, в случае инициативного бюджетирования - это возможность подачи заявки на участие онлайн, и, в дальнейшем, отслеживания ее статуса, а также наличие подробных отчетов по уже реализованным проектам.

Результаты оценки всех ресурсов каждого региона были просуммированы и построен общий рейтинг. Результаты исследования демонстрируют, что на сегодняшний день сохраняются значительные диспропорции в региональном развитии электронного участия. Это относится не только к общему баллу, но и к каждому типу электронного участия в отдельности. Общий балл по регионам на сегодняшний день колеблется от 0 до 83 баллов на региональном уровне и от 0 до 62 на муниципальном. Совокупная оценка регионов (включая и региональный и муниципальный уровни) составляет от 9 до 115 баллов.

Баллы, набранные каждым регионом за счет муниципальных и региональных порталов, также были просуммированы, был построен общий индекс развитости электронного участия. В соответствии с методикой, регионы были разделены на три типа: с высоким (от 60 баллов и более), средним (от 40 до 60 баллов) и низким (менее 40 баллов) уровнем развития ресурсов.

В настоящее время развитыми в отношении электронного участия можно считать 23 субъекта РФ (с учетом и региональных и муниципальных ресурсов - см. рис. 2). В среднем эти регионы имеют от 5 до 9 каналов электронного участия с достаточно высоким качеством реализации, представленных на двух уровнях власти.

В большинстве случаев перечень ресурсов в развитом регионе включает в себя:

реализованный в качестве отдельного портала ресурс типа «Открытый бюджет»; 
ресурс, посвященный инициативному бюджетированию, реализованный в виде портала или раздела на сайте ответственного органа власти;

портал сообщений о проблемах (в большинстве случаев он является кроссплатформенным ресурсом, сочетающим в себе функции портала проблем, электронных петиций и/или электронных голосований);

в более редких случаях организован отдельный портал для краудсорсинговых проектов.

На сегодняшний день уверенными лидерами можно считать Ханты-Мансийский Автономный округ (115 баллов, 9 ресурсов), Сахалинскую область (100 баллов, 7 ресурсов), Мурманскую область (90 баллов, 7 ресурсов), Рязанскую область (89 баллов, 7 ресурсов), Пермский край (85 баллов, 7 ресурсов), Москву (85 баллов, 5 ресурсов). Замыкают десятку лидеров Ленинградская, Калужская, Липецкая и Нижегородская области.

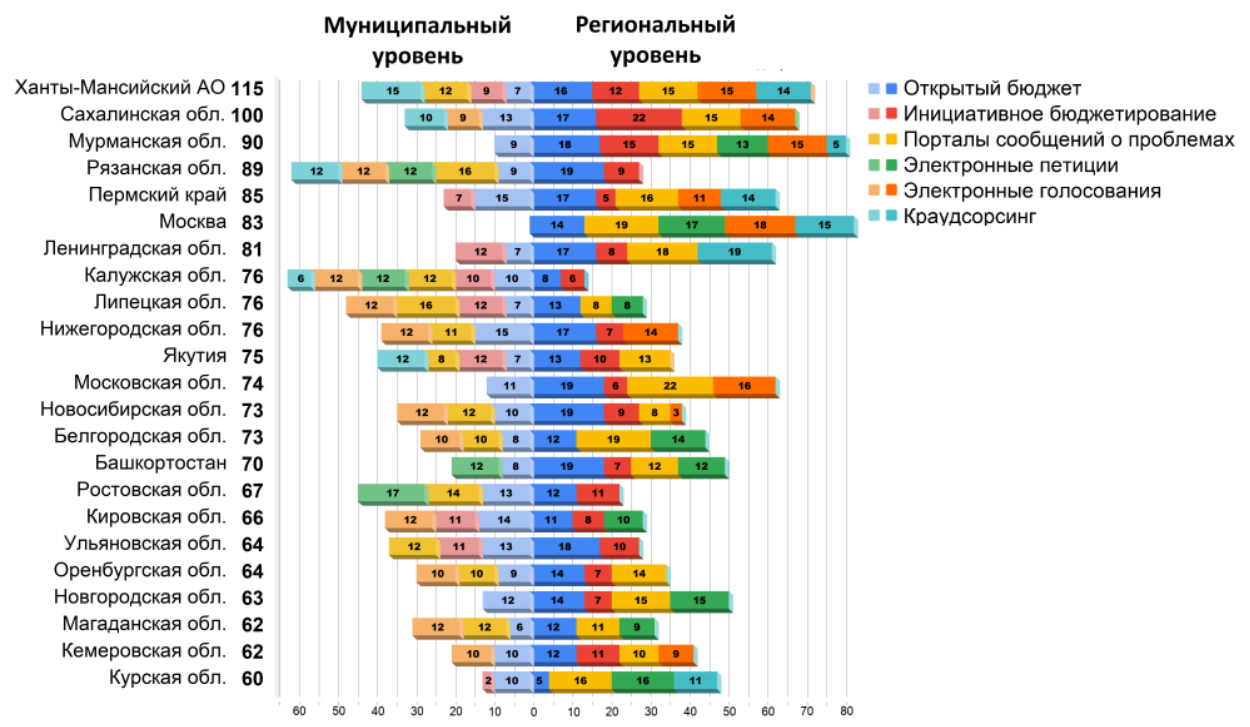

Рис. 2. Регионы с высоким уровнем развития электронного участия (декабрь 2019, данные ЦТЭП ИДУ Университета ИТМО)

Большинство регионов вошло в число лидеров за счет наличия нескольких качественных региональных ресурсов. Однако, имеются и исключения - например, в Рязанской, Калужской и Липецкой областях преобладают муниципальные порталы. Калужская область является единственным регионом, в котором на муниципальном уровне представлены все 6 каналов электронного участия. На региональном уровне единственным таким регионом является Мурманская область. Москва - единственный регион, вошедший в число лидеров, при полном отсутствии ресурсов на местном уровне, что объясняется спецификой организации местного самоуправления в городах федерального значения. В Московской, Нижегородской и Курской областях на местном уровне представлено только по одному ресурсу.

В группу со средним уровнем развития вошло 24 региона, имеющие от 4 до 6 ресурсов со средней и низкой реализацией (рис. 3). У регионов этой группы стабильно представлены «Открытый бюджет» и ресурсы по инициативному бюджетированию. Примерно в половине регионов функционируют порталы проблем, реже - ресурсы других типов. Количество региональных и местных порталов в этой группе распределилось примерно одинаково. Муниципальные ресурсы значительно преобладают в Томской, Ивановской, Тюменской областях, региональные - в Санкт-Петербурге (город федерального значения), Тульской и Курганской областях, а также в Республике Карелия. 
В наиболее многочисленную группу вошло 38 регионов с низким уровнем развития, что составляет $44 \%$ регионов страны (рис. 4).

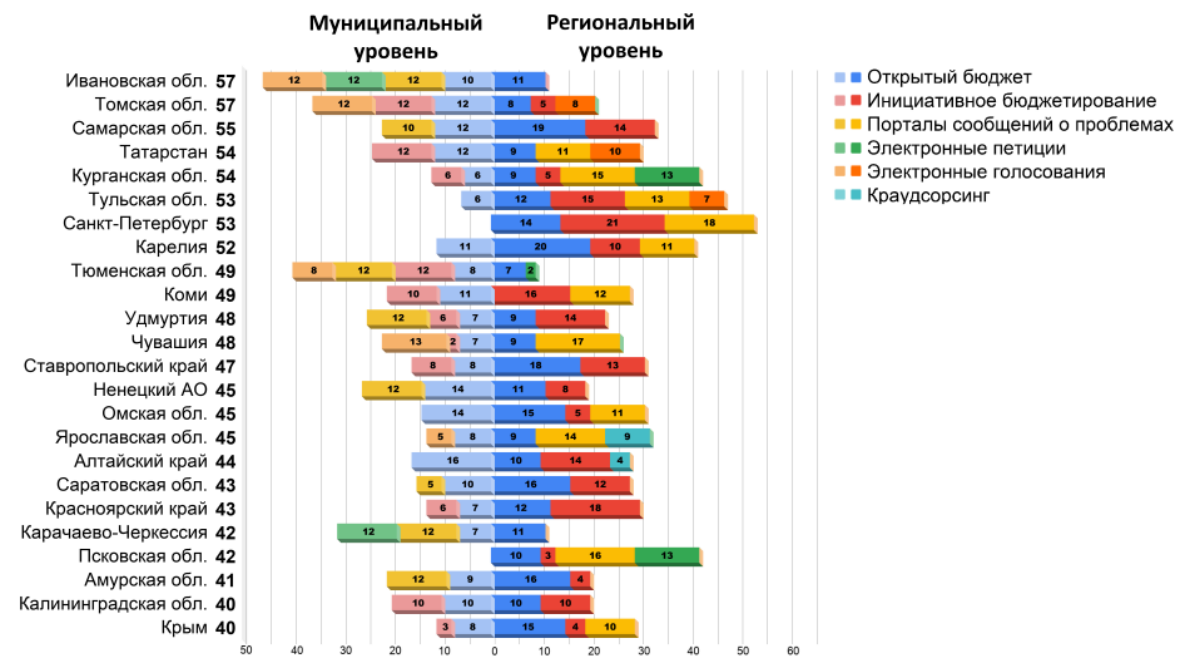

Рис. 3. Регионы со средним уровнем развития электронного участия (декабрь 2019, данные ЦТЭП ИДУ Университета ИТМО)

Регионы данной категории имеют от 1 до 4 порталов с весьма низким качеством реализации. В большинстве случаев это ресурсы «Открытый бюджет» и инициативное бюджетирование.

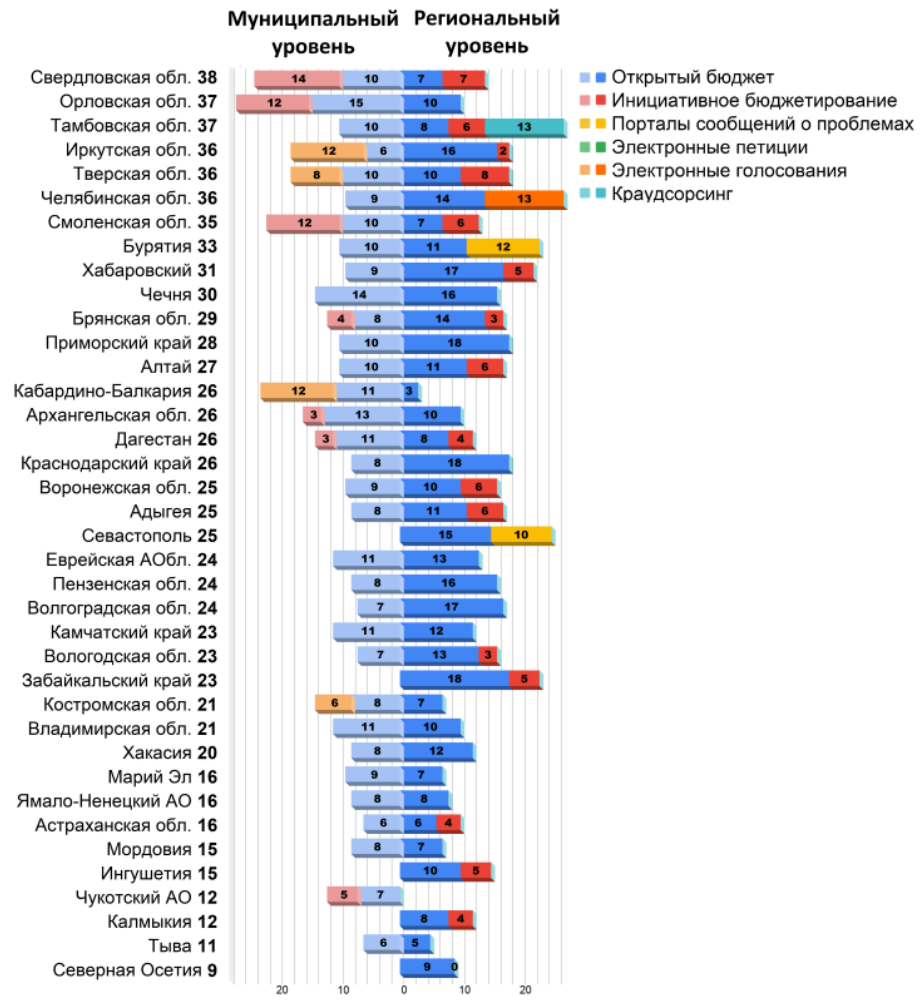

Рис. 4. Регионы с низким уровнем развития электронного участия (декабрь 2019, данные ЦТЭП ИДУ Университета ИТМО) 
Иные типы ресурсов в этой группе встречаются в единичных случаях. В десятку регионов, набравших наименьшее количество баллов, вошли: Республика Хакасия (20), Астраханская область (16), Ямало-Ненецкий АО (16), Республики Марий-Эл (16), Ингушетия (15), Мордовия (15), Калмыкия (12), Чукотский АО (12), Тыва (11) и Северная Осетия (9). Последняя является единственным регионом, имеющим всего один ресурс.

Был также рассчитан средний результат по федеральным округам (рис. 5). Полученное значение соответствует среднему результату всех регионов, располагающихся в федеральном округе. Примерно с одинаковым результатом лидируют сразу 4 округа: Центральный (52 балла), Приволжский (52), Уральский (52) и Северо-Западный (51). Следует отметить, что в Северо-Западном федеральном округе с большим отрывом преобладают региональные ресурсы, а местные почти не развиты. В Сибирском (42) и Дальневосточном (41) округах, следующих на втором месте, большинство регионов относится к группе со средним уровнем развития. При этом присутствует небольшое число регионов, где уровень развития высокий - на Дальнем Востоке таким регионом является Сахалинская область (100), а в Сибири - Якутия (75), Новосибирская (73) и Кемеровская (65) области. К сожалению, наиболее плачевна ситуация в Южном (30) и Северо-Кавказском (28) федеральных округах. Здесь электронное участие практически отсутствует или очень слабо развито. Единственным южным регионом, относящимся к группе развитых, является Ростовская область (67).

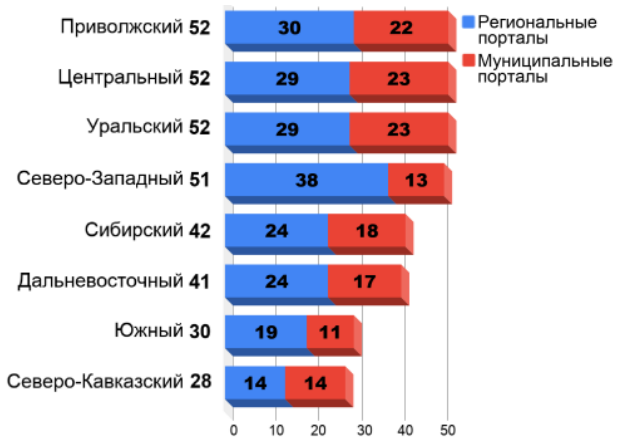

Рис. 5. Уровень развития электронного участия по Федеральным округам (декабрь 2019, данные ЦТЭП ИДУ Университета ИТМО)

В завершении описания основных результатов нашего мониторингового исследования следует обозначить дальнейшие планы. Любое исследование, предполагающее формирование рейтингов, представляет интерес, когда есть возможность видеть общую картину развития исследуемого явления в динамике. К сожалению, сейчас отсутствует возможность адекватного сопоставления данных мониторинга, осуществленного в конце 2019 г. с данными, полученными нами при обследовании сайтов в 2017 и 2018 гг. по причине кардинального изменения методики мониторинга.

Исследовательская группа Центра технологий электронного правительства Института дизайна и урбанистики Университета ИТМО планирует в ноябре-декабре 2020 г. провести вторую волну оценки по представленной методике и представить данные в динамике развития за один год (2019-2020 гг.).

\section{4. Заключение}

По результатам представленного исследования можно сделать несколько основных выводов, как с методологической, так и с содержательной точки зрения.

Во-первых, результаты исследования демонстрируют применимость разработанной методологии к анализу электронного участия в России. Используемая методика позволяет 
проводить сопоставление двух уровней власти - муниципального и регионального, а также нескольких каналов электронного участия, чем достигается комплексное видение ситуации. Полученные результаты могут в дальнейшем использоваться как для количественного сравнительного анализа, так и для глубокого изучения отдельных случаев успешного и неудачного внедрения партисипаторных практик. Кроме того, методика оценивает развитие электронного участия на разных этапах процесса принятия решений, что позволяет отслеживать отдельные «узкие места» в развитии регионального или муниципального электронного участия. Конечно, остаются и проблемы, которые предстоит решить на следующих этапах исследования: прежде всего, речь идет о сложностях в выявлении реального влияния электронного участия на процесс принятия управленческих решений, а также в определении уровня вовлеченности граждан в изучаемые партисипаторные каналы.

Во-вторых, предварительные результаты мониторинга подтвердили наличие существенных диспропорций регионального и муниципального развития электронного участия в России: как с точки зрения разнообразия каналов, предоставляемых гражданам в разных городах и субъектах, так и с точки зрения качества их функционирования. Общим выводом является то, что на данный момент более активно развиваются «информационные» формы электронного участия, что вполне естественно, учитывая весьма затянувшийся начальный этап формирования этой экосистемы, еще не достигшей оптимального уровня институционализации. Важность институциональной поддержки была выявлена на примере ресурсов инициативного бюджетирования и «открытого бюджета». В ходе исследования было выявлено широкое распространение этого типа ресурсов, что в первую очередь можно объяснить активной позицией Минфина России, активно внедряющего эти практики и инициировавшего процесс согласования специального законопроекта, регулирующего инициативное бюджетирование.

В дальнейшем команда исследователей планирует продолжение ежегодного мониторинга в сочетании с применением качественных методов (фокус-группы, полуструктурированные интервью и экспертные опросы) с целью выявления факторов способствующих и препятствующих развитию механизмов электронного участия в России на региональном и местном уровнях.

Работа выполнена при поддержке Российского научного фонда, проект №18-18-00360 «Электронное участие как фактор динамики политического процесса и процесса принятия государственных решений».

\section{Литература}

[1] Berntzen L., Olsen M. G. Benchmarking e-government - a comparative review of three international benchmarking studies // Third International Conference on Digital Society. Proceedings. 2009. P. 77-82. DOI: 10.1109/ICDS.2009.55.

[2] Fedotova O., Teixeira L., Alvelos H. E-participation in Portugal: evaluation of government electronic platforms // Procedia Technology. 2012. Vol. 5. P. 152-161. DOI: 10.1016/j.protcy.2012.09.017.

[3] Vidiasova L. The applicability of international techniques for E-participation assessment in the russian context // Digital Transformation and Global Society. Communications in Computer and Information Science book series (CCIS). Springer, 2016. Vol. 674. P. 145154. DOI: 10.1007/978-3-319-49700-6_15.

[4] Chugunov A. V., Kabanov Y. Evaluating e-participation institutional design. A pilot study of regional platforms in Russia // Electronic Participation. Lecture Notes in Computer Science (including subseries Lecture Notes in Artificial Intelligence and Lecture Notes in Bioinformatics) LNCS. Springer, 2018. Vol. 11021. P. 13-25. DOI: 10.1007/978-3-319-98578-7_2.

[5] Östling A. How democratic is e-Participation? // Proceedings of the International Conference 
for E-Democracy and Open Government, CeDEM 2011, Austria, 5-6 May 2011. P. 59-70.

[6] Цифровое политическое участие: эффективность электронных петиций интернетплатформ Change.org и РОИ (российская и кросс-культурная перспективы) / Под общ. ред.: Н. К. Радина. СПб: Издательство Нестор-История, 2019.

[7] Xenakis A., Loukis E. An investigation of the use of structured e-forum for enhancing eparticipation in parliaments // International Journal of Electronic Governance. 2010. Vol. 3 (2). P. 134-147. DOI: 10.1504/IJEG.2010.034092.

[8] Feeney M. K., Brown A. Are small cities online? Content, ranking, and variation of US municipal websites // Government Information Quarterly. 2017. Vol. 34 (1). P. 62-74. DOI: 10.1016/j.giq.2016.10.005.

[9] Bohman S. Information technology in eParticipation research: a word frequency analysis // Electronic Participation. Lecture Notes in Computer Science (LNCS). Springer, 2014. Vol. 8654. P. 78-89). DOI: 10.1007/978-3-662-44914-1_7.

[10]Easton D. An approach to the analysis of political systems // World politics. 1957. Vol. 9 (3). P. 383-400.

[11]Чугунов А.В., Кабанов Ю.А., Федяшин С.В. Развитие электронных приемных в регионах Российской Федерации: результаты пилотного исследования в 2017-2018 гг. // Информационные ресурсы России. 2019. № 3. С. 32- 36.

[12]Чугунов А.В. Взаимодействие власти и граждан в институциональной среде электронного участия // Власть. 2017. Т. 25, № 10. - С. 59-66.

[13]Kabanov Y., Sungurov A. E-Government development factors: evidence from the russian regions // Digital Transformation and Global Society. Communications in Computer and Information Science book series (CCIS). Springer, 2016. Vol. 674. P. 85-95. DOI: 10.1007/978-3-319-49700-6_10.

\title{
Monitoring of E-Participation Resources: Methodology and Some Results
}

\author{
Yu. A. Kabanov ${ }^{1,2}$, G. O. Panfilov ${ }^{1}$, A. V. Chugunov ${ }^{1}$ \\ ${ }^{1}$ ITMO University, ${ }^{2}$ HSE University- St. Petersburg
}

The article presents the main results of a comprehensive study of the resources of electronic participation in the regions of Russia, carried out in December 2019. The study was conducted using a methodology that allows us to evaluate various web resources of electronic participation and make cross-regional and cross-platform comparisons. The methodology was applied to evaluate 198 regional and 155 municipal resources of six basic types in all 85 regions of Russia. As a result, a rating of regions was built according to the general level of development of electronic participation: 23 regions with a high level of development of resources, 24 with an average level and 38 regions with a low level were identified. The results of the study confirmed the presence of significant imbalances in regional and municipal development of electronic participation in Russia: both from the point of view of the diversity of channels provided to citizens in different cities and regions, and from the point of view of the quality of their functioning. The general conclusion is that at present "informational" forms of electronic participation are more actively developing. In the future, it is planned to conduct annual monitoring of the development of electronic participation using this methodology in combination with qualitative analysis methods.

Keywords: information resources, electronic participation portals, e-participation, Russian regions, monitoring, rating

Reference for citation: Kabanov Y., Panfilov G.O., Chugunov A.V. Monitoring of EParticipation Resources: Methodology and Some Results // The State and Citizens in the Electronic Environment. Vol. 4 (Proceedings of the XXIII International Joint Scientific 
Conference «Internet and Modern Society», IMS-2020, St. Petersburg, June 17-20, 2020). St. Petersburg: ITMO University, 2020. P. 61-72. DOI: 10.17586/2541-979X-2020-4-61-72

\section{Reference}

[1] Berntzen L., Olsen M. G. Benchmarking e-government - a comparative review of three international benchmarking studies // Third International Conference on Digital Society. Proceedings. 2009. P. 77-82. DOI: 10.1109/ICDS.2009.55.

[2] Fedotova O., Teixeira L., Alvelos H. E-participation in Portugal: evaluation of government electronic platforms // Procedia Technology. 2012. Vol. 5. P. 152-161. DOI: 10.1016/j.protcy.2012.09.017.

[3] Vidiasova L. The applicability of international techniques for E-participation assessment in the russian context // Digital Transformation and Global Society. Communications in Computer and Information Science book series (CCIS). Springer, 2016. Vol. 674. P. 145154. DOI: 10.1007/978-3-319-49700-6_15.

[4] Chugunov A. V., Kabanov Y. Evaluating e-participation institutional design. A pilot study of regional platforms in Russia // Electronic Participation. Lecture Notes in Computer Science (including subseries Lecture Notes in Artificial Intelligence and Lecture Notes in Bioinformatics) LNCS. Springer, 2018. Vol. 11021. P. 13-25. DOI: 10.1007/978-3-31998578-7_2.

[5] Östling A. How democratic is e-Participation? // Proceedings of the International Conference for E-Democracy and Open Government, CeDEM 2011, Austria, 5-6 May 2011. P. 59-70.

[6] Digital political participation: the effectiveness of electronic petitions on the Internet platforms Change.org and ROI (Russian and cross-cultural perspectives) / Editor: N.K. Radina. St. Petersburg: Publishing House Nestor-History, 2019.

[7] Xenakis A., Loukis E. An investigation of the use of structured e-forum for enhancing eparticipation in parliaments // International Journal of Electronic Governance. 2010. Vol. 3 (2). P. 134-147. DOI: 10.1504/IJEG.2010.034092.

[8] Feeney M. K., Brown A. Are small cities online? Content, ranking, and variation of US municipal websites // Government Information Quarterly. 2017. Vol. 34 (1). P. 62-74. DOI: 10.1016/j.giq.2016.10.005.

[9] Bohman S. Information technology in eParticipation research: a word frequency analysis // Electronic Participation. Lecture Notes in Computer Science (LNCS). Springer, 2014. Vol. 8654. P. 78-89). DOI: 10.1007/978-3-662-44914-1_7.

[10]Easton D. An approach to the analysis of political systems // World politics. 1957. Vol. 9 (3). P. 383-400.

[11]Chugunov A.V., Kabanov Yu.A., Fedyashin S.V. The development of electronic participation in the regions of the Russian Federation: the results of a pilot study in 20172018 // Information resources of Russia. 2019. Vol. 3.P. 32-36.

[12]Chugunov A.V. The interaction of government and citizens in the institutional environment of electronic participation // Power. 2017. Vol. 25 (10). P. 59-66.

[13]Kabanov Y., Sungurov A. E-Government development factors: evidence from the russian regions // Digital Transformation and Global Society. Communications in Computer and Information Science book series (CCIS). Springer, 2016. Vol. 674. P. 85-95. DOI: 10.1007/978-3-319-49700-6_10. 